\title{
Sixty years of change in avian communities of the Pacific Northwest
}

Jenna R Curtis, W Douglas WDR Robinson

Bird communities are influenced by local and regional processes. The degree to which communities are dynamic has implications for projecting responses in community composition as birds track geographic shifts of their habitats. Historic datasets offer a legacy of information that can be used to quantify changes over time in avian community composition. A rare, highly-detailed avian survey of multiple habitat types in the Willamette Valley, Oregon, was conducted in 1952. We resurveyed the same sites in 2013 and evaluated patterns of community change: stability, turnover, diversity decay and increasing biodiversity. We compared alpha, beta, and gamma diversity between survey periods and evaluated shifts in categorical abundances of species. Most patterns of change were consistent with community turnover. Nearly $50 \%$ of species were replaced over six decades, with increased species richness and decreased evenness at local and regional spatial extents. Patterns of regional species turnover reflected local turnover. Evidence that local shifts in habitat structure drove bird community change were not strongly supported, although historic data on habitats within study plots were limited to macrolevel aerial photographs. Thus, regional factors are likely to have played important roles determining species composition and abundance. 
1 Jenna R. Curtis*

2 Department of Fisheries \& Wildlife, Oregon State University, Corvallis, Oregon, USA

3 W. Douglas Robinson

4 Department of Fisheries \& Wildlife, Oregon State University, Corvallis, Oregon, USA

5 * Corresponding author: Jenna R. Curtis

6104 Nash Hall, Oregon State University, Corvallis, OR 97331, 503-559-6094,

7 jenna.curtis@oregonstate.edu

\section{INTRODUCTION} central to the conservation of ecosystems (Vitousek et al., 1997). Birds are especially responsive to environmental variation (Temple \& Wiens, 1989; Crick, 2004). Change over time in species richness and patterns of abundance within local bird communities can be indicative of environmental change (Vale, Parker \& Parker, 1982; Root, 1988; Crick, 2004), local habitat variation (Knick \& Rotenberry, 2000; Brown et al., 2001; Rotenberry \& Wiens, 2009), or immigration and extinction at a regional level (Ricklefs, 1987; Loreau \& Mouquet, 1999). Both habitat characteristics and regional species assemblages influence local species communities, but the degree to which such relationships are dynamic over decades is not well understood. Detailed, long-term data capable of quantifying change within local communities are rare. Yet such data are necessary to empirically test predictions of community change (Igl \& Johnson, 2005; Tingley \& Beissinger, 2009).

Previous studies suggest several general, non-exclusive ways in which communities can change, particularly in systems experiencing increasing anthropogenic pressure (Catterall et al., 2010; Shultz, Tingley \& Bowie, 2012). Avian communities are generally expected to vary over time, as birds respond quickly to environmental change (Temple \& Wiens, 1989). However, some communities may express more long-term stability than others. Biologically diverse communities may be more stable, or resilient to change in the face of species invasion or population fluctuations, than simpler communities (MacArthur, 1955; Elton, 1958). While constancy in communities is unexpected, the extent to which communities change over time may be influenced by community composition, structure, or diversity (McCann, 2000). 
32 disturbance or urbanization (Beissinger \& Osborne, 1982; Strohbach, Hrycyna \& Warren, 2014).

33 This pattern has been referred to as "diversity decay" (Catterall et al., 2010). Homogenization of

34 communities may also occur when an influx of invasive, generalist species across habitats

35 reduces diversity between areas, skewing abundances in favor of common invaders (McKinney \&

36 Lockwood, 1999; Davey et al., 2012). Though invasion and homogenization can temporarily

37 increase overall species richness, a pattern of systematic increase in biodiversity is rarely posited

38 in scientific literature, despite evidence some urban environments support higher species

39 diversity (Marzluff, 2014).

40 Fluctuations in individual abundances may result in some species going locally extinct as

41 other species colonize. This pattern of "species turnover" produces changes in community

42 composition over time without significant changes in species richness (Diamond, 1969; Parody,

43 Cuthbert \& Decker, 2001; Catterall et al., 2010; Shultz, Tingley \& Bowie, 2012). Pronounced

44 turnover of biological systems has been observed across the globe (Dornelas et al., 2014), amidst

45 range shifts and species losses (Vitousek et al., 1997; Thomas \& Lennon, 1999). Yet there

46 remains disagreement as to which of these patterns is likely to describe long-term avian

47 community change at smaller spatial extents. Long-term avian surveys on multiple geographic

48 extents, coupled with assessments of habitat change, may provide the best opportunity to test the

49 applicability of these different models in a variety of systems

50 We resurveyed sites from a 60-year-old historic dataset. This dataset is uniquely valuable

51 because raw count data from each survey of each site were published in Richard Eddy's (1953)

52 master's thesis. Our objective was to evaluate the nature of avian community change in the

53 Willamette Valley, Oregon, and to characterize long-term variation in avian diversity between

54 and among different habitats. We compared alpha, beta, and gamma diversity, as well as species

55 turnover and categorical abundance levels. Changes in land use and habitat were measured using

56 aerial photographs and satellite imagery. Breeding Bird Survey data from western Oregon were

57 used to assess to what degree local differences in alpha and beta diversity between eras agreed

58 with regional gamma diversity. Overall, we evaluated to what degree observed results agreed

59 with any theoretical patterns of community change.

METHODS

61 Historic Avian Surveys 
In 1952, Richard Eddy surveyed birds at 6 sites within $50 \mathrm{~km}$ of Corvallis, Oregon (Eddy, 1953). Sites ranged in size between 8 and 20 hectares. Eddy non-randomly selected sites to represent 6 habitat types: coniferous, oak woodland, marsh, mixed deciduous, riverine/riparian, and "brushy." The objective of Eddy's study was to characterize the summer bird community around Corvallis (Eddy, 1953). His thesis was the first to provide quantitative information on the abundances of birds in the area. He did not measure vegetation, but qualitatively described presence of dominant tree and shrub species. Eddy recorded the number and species of birds observed by walking through a given site for 2 hours between 0500 and 1000 . He repeated this method 10 times for each site, visiting each site every 2-13 days in a non-systematic fashion starting the second week of June through August 24 (Eddy, 1953). Two sites were occasionally visited within a single day. Eddy (1953) reported using $8 \times 25$ power binoculars to observe birds. Because many commonly heard but rarely seen species such as Pacific Wren and Hermit Warbler were absent from his lists, we suspect Eddy relied mostly, if not entirely, upon visual detections (Curtis 2015).

\section{Modern Surveys}

Eddy did not provide maps of his survey sites. We relocated each historic site as accurately as possible using Eddy's site descriptions and aerial photographs of Benton County from 1956 (US Department of Agriculture, Farm Service Agency, 1956). We could not relocate the "brushy" site based on his descriptions, so did not resurvey that habitat. For two sites, his descriptions were sufficient to establish the general location but not the actual plot boundaries. We identified "likely areas" adjacent to the selected survey areas that contained the same habitat types as our plots. These surrounding areas were akin to buffers around the plots we surveyed and could include some of the habitat surveyed by Eddy in 1952. We compared bird communities in the 2 sites to adjacent "likely areas" to confirm site placement did not affect survey results (Appendix S1).

We used ArcGIS (ESRI, 2013) to designate site boundaries and overlaid a 200m square grid aligned with the longest axis of each site. We spot-mapped each of the 5 relocated sites 5 times during the 2013 breeding season beginning mid-May and ending the first week of July. We used the spot mapping protocol described in (Bibby et al., 2000). Beginning within 10 minutes of sunrise, we systematically walked across each site from grid point to grid point until the entire area was surveyed. Spot mapping replicates Richard Eddy's area search methods and collects 
93 identical information, but additionally records location and observation data for every detection

94 within the site. We recorded the geographic locations, species, sex, number of individuals,

95 detection method (visual vs auditory), and any relevant territorial or breeding behavior of all

96 birds encountered during a survey period. We did not conduct surveys on days with heavy rain.

97 Our objective was to survey birds during the breeding season when detectability is

98 highest and local populations of breeding adults are least influenced by non-breeding birds

99 moving through the landscape (Ralph, Sauer \& Droege, 1998). Detectability of many species

100 may decline after breeding activities cease. Most breeding activity in Oregon occurs from mid-

101 May through early July (Marshall, Hunter \& Contreras, 2003). Eddy surveyed birds from June

102 through August. It was necessary to restrict data comparisons to Eddy's first 5 visits to each site

103 because his last 5 visits fell outside the primary breeding season. Detections from the last 5 visits

104 in Eddy's dataset were likely to be affected by reduced detectability of non-singing local

105 breeding birds, as well as the presence of passage migrants or post-fledging family groups. We

106 evaluated the effects of reducing the number of visits and found they were minimal (Curtis,

107 2015). Because abundances and detectability remain generally stable throughout the breeding

108 season (Ralph, Sauer \& Droege, 1998), it is unlikely beginning modern surveys 2 weeks earlier

109 than historic surveys unduly influenced our results.

\section{Regional Breeding Bird Surveys}

111 To address questions regarding the spatial extent of changes observed in bird

112 communities, we evaluated patterns of community change on a regional level. The regional avian

113 community was defined by 10 Breeding Bird Survey (BBS) routes within the Willamette and

114 northern Umpqua valleys selected for their similarity to geographic features and habitat

115 surrounding Corvallis, Oregon. Routes ranged between 17 and $134 \mathrm{~km}$ of Corvallis. These routes

116 (and BBS route number) were: Tualatin (002), Umpqua (018), Days Creek (026), Adair (033),

117 Scio (034), Dayton (040), Elkton (050), Canby (202), Salem (237), and Lorane (243). Individual

118 route data was downloaded from the USGS Patuxent Wildlife Research Center FTP site (USGS

119 Patuxent Wildlife Research Center, 2013). All years of available data between 1966 and 2012 for

120 a given route were used for analysis.

\section{Environmental Traits}

122 To quantify changes in land use and vegetation cover between historic and modern

123 surveys, we scanned high-resolution digital images of 1956 aerial photographs from Benton 
124 County (US Department of Agriculture, Farm Service Agency, 1956). We overlaid images onto a $1251 \mathrm{~m}$ resolution satellite photograph of Oregon from 2012 (US Department of Agriculture, Farm

126 Service Agency, 2012). We visually classified all habitat cover within $150 \mathrm{~m}$ of each site for both

127 survey eras based on observable physical characteristics of the vegetation. We drew freehand

128 polygons to mark the boundaries between vegetation classes. This approach circumvented the

129 limitations associated with computer-based modelling and assigning land cover classes over pre-

130 established pixel cells (US Geological Survey, 2012). Each polygon was classified down to the

131 Macrogroup level using the US National Vegetation classification system (US Geological

132 Survey, 2012). For cases where the vegetation class for a given area was unclear, landscape data

133 from the US Gap Analysis Project (US Geological Survey, 2012) was consulted to help

134 determine the most likely classification for that polygon. Mean elevation, area in square meters,

135 and percent cover of each land use and vegetation classification for each site were calculated

136 using ArcGIS (ESRI, 2013). We compared percent cover values between years to quantify

137 changes in habitat cover for each site.

\section{Statistical Analysis}

139 All statistical analyses were performed in program R (R Core Team, 2013). Eddy's use of 140 only visual detections was realized after an initial comparison of the datasets. It was necessary to 141 remove non-visual detections from the modern data to make them comparable to the historic 142 dataset. Without non-visual detections, raw counts of individuals from the modern data were 143 inaccurate because many individual birds were identified aurally and no effort was expended to 144 visually confirm identifications. Therefore, when applicable, we used both datasets including and 145 omitting non-visual detections for statistical analyses. Species richness estimates, accumulation 146 curves, and diversity indices were obtained using the package "vegan" (Oksanen et al., 2013). 147 Species diversity comparisons. To account for undetected species, we estimated actual 148 species richness using Chao's first estimator ("Chao 1"; (Chao, 1984). Chao 1 estimates richness 149 based on number of observed species and number of species seen only once or twice during a 150 survey period.

151 Alpha diversity is a metric of site-specific species variety. We limited our alpha diversity

152 index analyses to birds detected at least twice during a survey year across all sites ( $n=102$ all 153 detections, 91 visual only). Removing the rarest species (singletons detected only once during 154 our modern surveys) reduced noise in the data and eliminated species that were not using the 
155 sites for breeding. We calculated compound alpha diversity for total number of individuals of 156 each species observed at a given site during a survey era using the inverse Simpson's diversity

157 (1/D) index. Simpson's inverse is the reciprocal of the chance that two randomly-sampled

158 individuals will be of the same species. 95\% confidence intervals for inverse Simpson's diversity

159 were obtained by percentile bootstrapping data from a given site and survey period for 9999

160 iterations (Hammer, 2013). Inverse Simpson's indices between survey periods were compared

161 using paired t-tests under the null hypothesis that the modern community diversity of a site was

162 not significantly different from the historic diversity (Brower, Zar \& von Ende, 1998; Hammer, 163 2013).

164 Beta diversity uses metrics of dissimilarity to investigate differences between multiple

165 communities separated by space and/or time (Anderson et al., 2011; Chase et al., 2011). We 166 quantified beta diversity using the modified Raup-Crick method ( $\beta_{\mathrm{RC}}$; (Chase et al., 2011). $\beta_{\mathrm{RC}}$ is

167 independent of changes in alpha diversity and does not depend on the number of species within

168 each community (Anderson et al., 2011). This approach evaluates whether pairs of communities

169 for a given time period are more or less different than chance. Calculations are based on the

170 number of species in each site and in the regional pool, as well as the proportion of sites

171 occupied by each species. We calculated beta diversity using the program $\mathrm{R}$ code provided by

172 Chase et al. (2011).

173 To identify significant differences in beta diversity among non-random pairs of

174 communities, it was necessary to compare against null communities generated by chance. To

175 derive null communities, we randomly sampled a number of species from the entire species pool

176 equal to the number of species for a given pair of sites. We estimated the probability that the

177 observed number of shared species in a pair of communities was equal to or lower than the null

178 expectation. This probability was re-scaled to a metric ranging from -1 to 1 , where communities

179 with lower values are less dissimilar than expected, and communities with higher values are

180 more dissimilar than expected (Chase et al., 2011). To compare beta diversity for communities

181 between years, we calculated pairwise dissimilarity matrices for all sites within a given year then 182 tested for differences in mean dissimilarity values using paired 2 -sample t-tests.

183 Turnover represents the instability of a species pool over time. Many measures of

184 turnover fail to account for non-detected species that may immigrate or go extinct from the local 185 species pool between years (Boulinier et al., 1998). For this study, species turnover was defined 
186 as the complement of the estimated total number of species shared between 2 time periods $(i$ and $187 j$ ) conditioned on the estimated total number of species during time $j$ (Nichols et al., 1998). The

188 number of shared species was estimated with the Chao 1 richness estimator using the abundance

189 data from time $i$ only for species also detected during time $j$. Because Chao 1 approximates

190 actual species richness, including an estimate of species missed by the surveyor, the result is a

191 conservative estimate of shared species richness that accounts for non-detected species. This

192 value was divided by Chao's estimate of species richness for time $j$ to produce the probability

193 that any given species at time $j$ was a species present during time $i$. The complement of this was

194 the estimated probability that a species is "new", or not present during the initial surveys. We

195 calculated turnover for each site as well as the entire study area between survey years. Estimates

196 of standard error were obtained by standard nonparametric bootstrapping of the data for 1000

197 iterations using the "boot" package in program R (Canty \& Ripley, 2014).

198 When examining species turnover on a regional level, it was necessary to use Chao's

199 estimate rather than observed richness due to the structure of regional BBS data. The estimated

200 number of shared species across all BBS routes was frequently as large as or larger than the

201 observed richness for the subsequent year. To reduce bias, the denominator on which the

202 estimate of richness is conditioned must be representative of the relevant species pool (Cam et

203 al., 2000). Because the area represented by the regional species pool was large, there was a

204 considerable discrepancy between observed and estimated species richness. Conditioning upon

205 estimated regional species richness for the second survey period produced a less biased estimate

206 of turnover compared to observed richness, and was more appropriate for examining regional

207 gamma diversity.

208 To investigate changes in gamma - or regional - diversity, we first defined the regional

209 species pool from which immigrations into the local sites might occur. Because the number of

210 BBS routes surveyed varied across years, we used individual-based rarefaction to generate

211 subsamples for each year after standardizing for differences in survey effort (Gotelli \& Colwell,

212 2001). Rarefaction was performed on all routes from a given year for 1000 iterations using

213 package "vegan" in Program R (Oksanen et al., 2013). Mean species richness was then estimated

214 for the rarefied samples from each year using Chao 1 (Chao, 1984). We calculated mean yearly

215 regional species turnover from the rarefied samples using a method similar to local turnover.

216 Durbin-Watson tests were used to test for autocorrelative structure in the data (Durbin \& 
217 Watson, 1950, 1951). When serial correlation was present, we used linear filtering to adjust the 218 data prior to fitting regression lines and estimating trends.

219 Changes in abundance. It was necessary to account for lack of direct comparability 220 between historic and modern estimates of abundance due to differences in observation methods. 221 To detect large shifts in abundances, we organized species into categorical levels of abundance. 222 We based categories on the mean number of individuals per visit to a site for a given year. 223 Species were classified as follows (mean number of individuals per visit provided in 224 parentheses): "rare" (up to 1.5 individuals per visit), "uncommon" (between 1.5 and 4.5 225 individuals per visit), "common" (between 4.5 and 10 individuals per visit), and "abundant" 226 (over 10 individuals per visit). Species with zero individuals per visit at a given site during one 227 of the survey eras were classified as "not detected" for that era.

228 We categorized changes in abundance between years. Trend classifications ranged from 229 "strongly declining" to "strongly increasing" based on both the direction and magnitude of the 230 shift in abundance category. Species that retained their historic categorical abundance 231 classification were classified as "no change". We tested for shifts in the distribution of species 232 among abundance categories across all sites between years using chi-square tests under the null 233 hypothesis that the overall distribution of species within categories was not different between 2341952 and 2013. For comparisons of abundance distributions at individual sites, we used Fisher's 235 exact tests because the assumptions of the chi-square test were not met. For species strongly 236 increasing or decreasing locally, we considered possible ecological explanations and compared 237 our results to regional BBS population trends. Trends were obtained from (Sauer et al., 2014), 238 who use a hierarchical model to calculate changes in annual indices of abundance.

\section{RESULTS}

\section{Land Use and Vegetation Cover}

241 To determine if environmental conditions at survey sites changed, we quantified 242 differences in the percent cover of multiple vegetation and land use classes. The amount and 243 direction of habitat change varied among sites (Figs. S1-S5). The Willamette River site 244 experienced some of the greatest overall changes in habitat percent cover. Historically this site 245 was nearly $50 \%$ wetland and approximately $30 \%$ open water. By 2013 , floodplain forest 246 dominated the site with $85 \%$ cover. Canopy in the burned portion (about $15 \%$ ) of the mature 
247 coniferous site closed, but was otherwise similar in structure. Both the mixed deciduous and oak 248 woodland sites experienced some canopy closure. The mixed deciduous site changed from 249 primarily riparian forest to a mixed forest/pasture habitat with nearly $50 \%$ deciduous cover.

250 Similarly, the oak woodland site lost almost 15\% deciduous cover to expanding coniferous 251 forest. Eddy (1953) did not quantify understory vegetation so we could not quantify changes in 252 habitat structure. In conjunction with an overall increase in coniferous canopy cover, the three 253 forest habitats remained forested, while the Willamette River floodplain site increased in forest 254 cover. The marsh site was superficially very similar, but Eddy's description indicates the marsh 255 was open to cattle grazing, which has now been eliminated.

\section{Species Diversity}

Stability and turnover predict species richness will remain the same, while diversity decay predicts richness will decrease. Observed species richness was higher in modern study sites compared to the historic surveys when aural detections were included (Table 1). Thirteen rare species were removed from historic dataset and 18 from the modern dataset, 14 of which were visually detected. After removing non-visual detections, observed species richness remained an average of 4.8 species higher than historic richness, except for the coniferous site, which decreased in richness. Estimates of species richness accounting for rare and undetected species showed significant increases in richness for the marsh and oak woodland sites.

Alpha diversity is linearly related to species richness, and should exhibit a similar response as richness under each pattern of community change. After removing rare species, the inverse of Simpson's diversity was an average of 4.8 higher for modern sites (Table 2). Across all sites, alpha diversity experienced a statistically significant increase between years (all detections: $t_{3905}=19.3, \mathrm{p}<0.001$; visual detections: $\left.t_{4379}=16.2, \mathrm{p}<0.001\right)$. The only significant site-specific increase occurred at the marsh site (all detections: $t_{2579}=23, \mathrm{p}<0.001$; visual detections: $\left.t_{2832}=20.9, \mathrm{p}<0.001\right)$. The coniferous and oak woodland sites both showed significant decreases in diversity considering only visual detections (coniferous: $t_{298}=-6.6, \mathrm{p}<$ 274 the mixed deciduous and Willamette River sites. Removing non-visual detections had the general 275 effect of decreasing modern alpha diversity to near or below historic values for all sites. This is 276 notable, considering richness was still higher in the modern era after removing non-visual 277 detections. 
Beta diversity, a measure of community dissimilarity among sites, should remain

279

280

281

282

283

284

285

286

287

288

289

290

291

292

293

294

295

296

297

298

299

300

301

302

303

304

305

306

307

308 constant with stability and turnover, and decrease with diversity decay. Accounting for differences in species richness, mean beta diversity for the historic period was 0.61 , while mean beta diversity for the modern period was 0.18 ( 0.19 visual only). While modern sites were more similar in community composition than their historic counterparts, beta diversity did not significantly differ between years (all detection types: $t_{3}=2.2, \mathrm{p}=0.12$; visual detections only: $t_{3}$ $=1.9, \mathrm{p}=0.16)$. Both survey periods showed less among-site similarity than expected by chance. We evaluated patterns of community turnover by quantifying the probability of species replacement between survey periods. Species turnover between 1952 and 2013 was high (Table 3). After removing rarities, only 48 species out of 102 species (39 out of 91 species, visual detections only) were present for both survey periods (Tables S1-S2). Turnover at individual sites was higher than turnover across the study area. The oak woodland site had the highest species turnover. Removing non-visual detections generally increased turnover values, with the exception of the Willamette River site.

We compared local community results to regional community change using individualbased rarefied BBS data for 10 selected routes with similar habitat. After accounting for differences in annual survey effort, trends in regional species richness agreed with local results (Fig. 1). Species richness across rarefied samples significantly increased from an estimated 69 species in $1968(\mathrm{SE}=10.1)$ to 97 species in $2012(\mathrm{SE}=10.6)$. The highest annual estimated species richness was 103 species $(\mathrm{SE}=10.8)$ in 2005. The estimate of overall regional turnover was similar to local turnover, with a $41 \%$ probability of species replacement over three decades $(\mathrm{SE}=7.7)$. Mean annual turnover over the 34 -year period was $16 \%$. Estimated annual turnover ranged from 11\% (multiple years) to $26 \%$ (between 1968 and 1969). There was a significant increasing trend in species richness over time after accounting for serial correlation. Regional species richness increased approximately 0.29 species per year between 1968 and 2012 (p < $0.001,95 \% \mathrm{CI}=0.13-0.45)$. Regional turnover did not exhibit serial correlation, and had a slight but non-significant decrease of $0.02 \%$ over time $(\mathrm{p}=0.51,95 \% \mathrm{CI}=-0.11-0.06 ;$ Fig. 1$)$.

\section{Abundance Comparisons}

Some patterns of community change predict avian abundances to decrease from urbanization or habitat loss. Considering all detection types, the majority of species in this study were increasing or strongly increasing (40 and 17 species, respectively; Table S3). Another 17 
309 species did not change in categorical abundance over time. 23 species were decreasing in

310 abundance. However, after removing non-visual detections, more birds were decreasing or

311 strongly decreasing in abundance ( 34 and 8 species, respectively). Only 38 visually detected

312 species increased in abundance to any degree. 11 species did not change in categorical

313 abundance based on visual detections.

314 The distribution of species among abundance categories shifted significantly over time

315 (all detections: $\chi^{2}{ }_{4}=10.35, p=0.04$; visual detections only: $\chi^{2}{ }_{4}=9.54, p=0.05$ ). Species were

316 more evenly distributed among abundance categories historically. Modern abundances were less

317 evenly distributed and had more species in the "rare" and "abundant" categories. There was

318 variation in the degree to which abundance distributions changed for each individual site. The

319 coniferous and oak woodland site both showed significant shifts in categorical avian abundances

320 regardless of detection type (coniferous site: all detections $p=0.03$, visual detections $p=0.002$;

321 oak woodland site: all detections $\mathrm{p}=0.03$, visual detections $\mathrm{p}<0.001$ ). The coniferous site

322 increased in abundant species, while the oak woodland site increased in rare species. The

323 Willamette River site increased in both abundant and rare species, with a loss in common

324 species; this shift was significant when all detection types were considered $(p=0.007)$.

\section{DISCUSSION}

In 1952, Richard Eddy conducted detailed avian surveys at 6 sites in Benton County,

327 Oregon. We resurveyed 5 of those sites six decades later to evaluate how and to what extent

328 avian community composition changed. Species turnover was high, and there was strong

329 evidence nearly half of the species detected during modern surveys were not present historically.

330 On a local scale, richness increased. Similar levels of turnover and increasing species richness

331 were evident on a regional extent. Our results paint a picture of dynamic species richness,

332 abundances, and overall community change.

333 Many challenges accompany the use of historic datasets (Igl \& Johnson, 2005; Tingley \&

334 Beissinger, 2009). We attempted to account for as many of these as possible through survey

335 methods and analyses. Our greatest challenge was lack of clarity regarding Eddy's detection

336 method. We suspect his dataset contains only visual detections. Most modern surveys emphasize

337 auditory detections, particularly in wooded habitats. Removing non-visually detected species

338 from our surveys provided a conservative estimate of modern avian diversity but improved our

339 ability to compare with Eddy's results. We found historic and modern survey efforts encountered 
340 species at similar rates and with similar thoroughness (Curtis, 2015). There was no evidence

341 omitting post-breeding season (late July and August) surveys from the historic dataset

342 significantly influenced our conclusions (Curtis 2015). We addressed the issue of uncertain site

343 placement by comparing diversity within sites to adjacent areas. There was no evidence that

344 changing site placement influenced results of modern surveys (Curtis 2015).

345 Although we addressed potential issues confounding our comparisons with Eddy's

346 surveys, the possibility remains that some changes were the result of methodological differences

347 or changes in detectability, rather than actual ecological changes. While insufficient historic

348 vegetation data and limitations associated with the interpretation of Eddy's data limit the

349 precision of conclusions, we found strong indications of community change during the last six

350 decades.

\section{Changes in Richness and Diversity}

352 Species richness increased over time at 4 of the 5 study sites. Local and regional

353 estimates of "true" species richness paralleled these observations. Though richness increased,

354 evenness and diversity both decreased, in some cases to a significant degree. Historic

355 communities had more species of intermediate abundance (common, uncommon), while modern

356 species tended to be either rare or abundant. This suggests higher species richness may be

357 associated with a decrease in community diversity when abundances vary over time (La Sorte \&

358 Boecklen, 2005). Simpson's index of diversity is sensitive to changes in evenness. An uneven

359 distribution of individual species abundances should result in lower calculated species diversity,

360 even if species richness increased over the same period. Additionally, variations in evenness may

361 have contributed to overall community instability over the past six decades (Mikkelson et al.,

362 2011).

363 In this study, beta diversity did not significantly change spatially. However, temporal

364 trends in beta diversity were mixed. Other long-term comparisons of avian communities

365 observed temporal declines in beta diversity (Catterall et al., 2010; Shultz, Tingley \& Bowie,

366 2012; Davey et al., 2013). Increases in species richness are frequently associated with decreases

367 in beta diversity because larger species pools share more species between sites (Davey et al.,

368 2013). After removing non-visual detections, beta diversity did slightly decrease between survey

369 periods. We detected a few species that colonized all sites since 1952, which contributed to this

370 decline. However, the slight decline in beta diversity was also attributed to encountering the 
371 same non-visually detected species across sites during the modern surveys. If the same species

372 (e.g., species whose behavior or physical characteristics made them difficult to see) consistently

373 failed to be visually observed by us at every site, then their removal should increase the

374 heterogeneity of the remaining visually detected species across sites.

375 Structural and Climatic Influences

376 We identified some degree of vegetation change during this study not characterized by

377 changes in percent cover of habitat types. Variation in vegetation structure and volume may

378 explain, to some extent, the observed changes in species assemblages and abundances (Vale,

379 Parker \& Parker, 1982; Holmes \& Sherry, 1988; Seavy \& Alexander, 2011). The oak woodland

380 and Willamette River sites experienced some of the most pronounced changes in vegetation and

381 land use cover. The Willamette River site transitioned from primarily urban-adjacent open grass

382 and wetlands (Eddy 1953), to a dense, closed-canopy floodplain forest. This site also had one of

383 the largest increases in species richness as well as the highest turnover rate. Nearly a third of the

384 oak woodland site is now coniferous forest. An increase in coniferous-associated species at this

385 site, including Pacific-slope Flycatcher (Empidonax difficilis) and Pacific Wren (Troglodytes

386 pacificus), may be attributed to changes in forest cover type (Hagar, McComb \& Emmingham,

387 1996).

388 At the marsh site, the elimination of grazing and changes in water management provided 389 more standing water for birds including Pied-billed Grebe (Podilymbus podiceps), Wood Duck

390 (Aix sponsa), and Tree Swallow (Tachycineta bicolor). Species historically detected at the

391 coniferous site - including Western Bluebird (Sialia mexicana), MacGillivray's Warbler

392 (Geothlypis tolmiei), and Ruffed Grouse (Bonasa umbellus) - exhibited decreasing abundances

393 following vegetation growth and canopy closure in the area of the site that was formerly burned

394 (Eddy 1953). Though the Western Bluebird and Ruffed Grouse are increasing regionally (Sauer

395 et al. 2014), local declines in these species (Table S1), as well as MacGillivray's Warbler, may

396 be associated with a loss of non-coniferous habitat (Hagar, 2007). It may be that some species

397 presences or absences were associated with changes in the surrounding vegetation community, as

398 suggested by previous studies (Vale, Parker \& Parker, 1982; Holmes \& Sherry, 2001; Seavy \&

399 Alexander, 2011), even if the fine details of such change are difficult to see in this study given

400 limited historic vegetation data. 
It is estimated temperatures in the Willamette Valley region increased by approximately $1.5^{\circ} \mathrm{C}$ over the past century (Environmental Protection Agency, 2015). Data from a single

403 Corvallis climate station suggest local temperature trends resembled regional trends (NOAA

404 National Climatic Data Center, 2015). However, it was not possible to quantify small-scale

405 climate change for our study sites. Increasing vegetation structure, density, or shade could

406 influence local temperatures independently of regional trends. Rising temperatures or

407 precipitation changes on a regional level may drive species range shifts and alter regional

408 community composition (Thomas \& Lennon, 1999; La Sorte \& Thompson III, 2007; Illán et al.,

409 2014). Nevertheless, we cannot evaluate rigorously the degree to which climate may have

410 influenced local species assemblages based on comparisons with these opportunistic historic

411 survey data. It is difficult to parse the effects of climate change on the observed bird

412 communities from local, site-specific factors.

413 Local and Regional Population Trends

414 Local community composition is frequently attributed to site-specific characteristics

415 rather than large-scale influences (Knick \& Rotenberry, 2000; Rotenberry \& Wiens, 2009).

416 While we detected some vegetation structure change, largely associated with succession after

417 removal of disturbances, overall land use and vegetation cover remained relatively stable across

418 survey sites. This supports the idea that regional community composition is important in

419 structuring local diversity (Ricklefs, 1987). A large regional species pool provides a greater

420 assortment of individuals capable of being recruited into local communities (Brown et al., 2001),

421 and may explain why regional gamma diversity complemented local changes in richness and 422 species composition.

423 Overall, local abundance trends reflected regional population trends. Species with 424 strongly decreasing local populations included Chipping sparrow (Spizella passerina), House 425 Sparrow (Passer domesticus), Nashville Warbler (Oreothlypis ruficapilla), and Northern Rough426 winged Swallow (Stelgidopteryx serripennis). All of these species were common or abundant in 4271952 but not detected during modern surveys. Other birds originally detected but not observed 428 during resurveys include Ring-necked Pheasant (Phasianus colchicus), Northern Bobwhite 429 (Colinus virginianus), and Common Nighthawk (Chordeiles minor). Statewide BBS trends for 430 these species are all negative and, in the case of Chipping Sparrow, Northern Bobwhite, and 431 Northern Rough-winged Swallow, population declines are quite strong (Sauer et al., 2014). 
Many species with strongly increasing populations on a local scale are also increasing

433 regionally (Sauer et al. 2014). It has been suggested that as species richness increases, dominant

434 species, or species with proportionally large numbers of individuals, also increase (La Sorte \&

435 Boecklen, 2005). In this study, several previously unobserved species now dominate the

436 community with high categorical abundance. New species, including European Starling (Sturnus

437 vulgaris), House Finch (Haemorhous mexicanus), and Brown-headed Cowbird (Molothrus ater),

438 are some of the most common species in the Willamette Valley (Hennings \& Edge, 2003).

439 Species not detected historically but frequently observed during modern surveys included House

440 Finch, Anna's Hummingbird (Calypte anna), and Acorn Woodpecker (Melanerpes

441 formicivorus). The remaining new species, such as Black Phoebe (Sayornis nigricans), Eurasian

442 Collared-Dove (Streptopelia decaocto), and Sharp-shinned Hawk (Accipiter striatus), tended to

443 be categorically rare, because either they were not established in the area (phoebe and collared-

444 dove), or they may now be easier to detect than historically (hawk).

445 Patterns of Community Change

446 Avian community diversity at 5 sites in the Willamette Valley, Oregon changed over the 447 course of 60 years, but the nature of this change was complex and not easily characterized. Our

448 results are most consistent with community turnover. Increases in species richness contrasted

449 decreases in species evenness and diversity, but the largest change was in community

450 composition. We observed less than half of historically occurring species. Turnover estimated

451 over all sites was a conservative measure of assemblage change because species extirpated from

452 one area may still have been detected at another site.

453 Estimates of turnover at individual sites were even higher; the odds of species persisting

454 within the local assemblage at any given site were between 25 and $40 \%$. These values agree with

455 those from other research. After 50 years of study, Parody et al. (2001) reported only $30 \%$ of

456 species were consistently present over time within communities. Diamond (1969) found species

457 turnover rates of 50-60\% after nearly half a century of community change. Likewise both

458 Catterall et al. (2010) and Shultz et al. (2012) determined turnover was the driving force of

459 community change over time, as neither species richness nor diversity significantly differed

460 between years. Across the globe, communities may undergo significant assemblage changes

461 without systematic loss of diversity (Dornelas et al., 2014). 
There was some evidence for a pattern of invasion and homogenization from our results.

463 Most species observed as increasing or strongly increasing in abundance did so across all sites.

464 Newly colonizing species may have contributed to skewed abundances by increasing numbers in 465 both the rare and abundant categories. Immigrant species such as European Starling and Brown466 headed Cowbird were observed at nearly every site. The result of this widespread species influx

467 may be the observed increases in richness and slight decrease in beta diversity over time. Further 468 monitoring is needed to evaluate whether new species invasions will ultimately reduce functional 469 and beta diversity as some models predict (McKinney \& Lockwood, 1999; Devictor et al., 2007;

470 Davey et al., 2013)

\section{Conclusion}

$472 \quad$ Novel communities are expected as species distributions adjust to changing

473 environmental conditions (Thomas \& Lennon, 1999; Williams \& Jackson, 2007). There is

474 concern the resulting communities will possess altered ecosystem functionality and challenge

475 species' abilities to adapt (Stralberg et al., 2009). An underlying implication is that communities

476 would otherwise remain static, or that modern species assemblages are comparatively more

477 natural than those resulting from climate change and anthropogenic disturbance. However, it is

478 difficult to say how much species assemblage variation could be expected even under "normal"

479 conditions (Magurran et al., 2010). Our study suggests communities are in a state of flux and

480 "re-shuffle" over decadal periods even with little macro-scale habitat change.

481 The community turnover observed in this study demonstrates long-term variability of

482 species composition. Drivers of community change may not always relate to climate, vegetation,

483 or human disturbance exclusively. Much has been said about the influence of site-specific

484 conditions on observed community composition (Knick \& Rotenberry, 2000; Rotenberry \&

485 Wiens, 2009). However, our results demonstrate the association between regional communities

486 and community change at smaller scales. Community turnover is an ecologically important

487 pattern useful for understanding the underlying mechanisms structuring communities (Chase et

488 al., 2011). Assemblage flux may contribute to community instability, even when richness

489 remains constant or increases, in cases where the addition of new species reduces evenness.

490 Population instability resulting from reduced evenness (Mikkelson et al., 2011) may drive other

491 local species to disappear, producing the observed community turnover. 

assemblage changes. Richard Eddy's (1953) dataset is the only one of such detail currently

494 known for the Pacific Northwest from that era, and provides us with a unique look at historic

495

496

497

498

499

500

501

502

503

504

505

506

507

508

509

510

511

512

513

514

515

516

517

518

519

520

521

522

523

524

525

526 avian communities. Some may consider the analytical challenges presented by historic datasets to be insurmountable. However, to discard past data because it no longer meets modern requirements is to ignore a valuable perspective on previous conditions. Historic data remind us that biological communities are in flux and may not be easily characterized by a few seasons of data collection. As more researchers seek ways to preserve biodiversity in the face of global climate change, historic datasets present an essential perspective on how community diversity varies over time.

\section{ACKNOWLEDGEMENTS}

We gratefully acknowledge Stuart Pimm, Gregory Mikkelson, Terry Root, and one anonymous reviewer who provided valuable comments and suggestions for earlier drafts of this manuscript. We thank John Alexander, Pat Kennedy and Jim Peterson for their advice during the design, analysis, and writing process. John Van Sickle and Bruce McCune provided statistical advice. Shelley Hansen allowed access to the mixed deciduous site through the OSU poultry facilities. Sharon Smythe, Tyler Hallman and Chad Marks-Fife accompanied and documented field surveys.

\section{REFERENCES}

Anderson MJ, Crist TO, Chase JM, Vellend M, Inouye BD, Freestone AL, Sanders NJ, Cornell HV, Comita LS, Davies KF. 2011. Navigating the multiple meanings of $\beta$ diversity: a roadmap for the practicing ecologist. Ecology letters 14:19-28.

Beissinger SR, Osborne DR. 1982. Effects of urbanization on avian community organization. Condor 84:75-83.

Bibby CJ, Burgress ND, Hill DA, Mustoe SH. 2000. Bird Census Techniques. London: Academic Press.

Boulinier T, Nichols JD, Sauer JR, Hines JE, Pollock KH. 1998. Estimating species richness: the importance of heterogeneity in species detectability. Ecology 79:1018-1028.

Brower JE, Zar JH, von Ende C. 1998. Field and laboratory methods for general ecology. Dubuque, Iowa: Wm. C. Brown Co.

Brown JH, Whitham TG, Morgan Ernest SK, Gehring CA. 2001. Complex Species Interactions and the Dynamics of Ecological Systems: Long-Term Experiments. Science 293:643650.

Cam E, Nichols JD, Sauer JR, Hines JE, Flather CH. 2000. Relative species richness and community completeness: birds and urbanization in the mid-Atlantic states. Ecological 
Applications 10:1196-1210.

Canty A, Ripley B. 2014. boot: Bootstrap R (S-Plus) Functions.

Catterall CP, Cousin JA, Piper S, Johnson G. 2010. Long-term dynamics of bird diversity in forest and suburb: decay, turnover or homogenization? Diversity and Distributions 16:559-570.

Chao A. 1984. Nonparametric estimation of the number of classes in a population. Scandinavian Journal of statistics 11:265-270.

Chase JM, Kraft NJ, Smith KG, Vellend M, Inouye BD. 2011. Using null models to disentangle variation in community dissimilarity from variation in $\alpha$-diversity. Ecosphere 2:1-11.

Crick HQP. 2004. The impact of climate change on birds. Ibis 146:48-56.

Curtis J. 2015. 60 years of avian community change in the Willamette Valley, Oregon. Master's Thesis. Corvallis: Oregon State University.

Davey CM, Chamberlain DE, Newson SE, Noble DG, Johnston A. 2012. Rise of the generalists: evidence for climate driven homogenization in avian communities. Global Ecology and Biogeography 21:568-578.

Davey CM, Devictor V, Jonzén N, Lindström Å, Smith HG. 2013. Impact of climate change on communities: revealing species' contribution. Journal of Animal Ecology 82:551-561.

Devictor V, Julliard R, Couvet D, Lee A, Jiguet F. 2007. Functional homogenization effect of urbanization on bird communiites. Conservation Biology 21:741-751.

Diamond JM. 1969. Avifaunal equilibria and species turnover rates on the Channel Islands of California. Proceedings of the National Academy of Sciences 64:57-63.

Dornelas M, Gotelli NJ, McGill B, Shimadzu H, Moyes F, Sievers C, Magurran AE. 2014. Assemblage time series reveal biodiversity change but not systematic loss. Science 344:296-299.

Durbin J, Watson GS. 1950. Testing for serial correlation in least squares regression: I. Biometrika:409-428.

Durbin J, Watson GS. 1951. Testing for serial correlation in least squares regression. II. Biometrika:159-177.

Eddy RH. 1953. Summer bird habitats in the Corvallis area, Willamette Valley, Oregon. Master's Thesis. Corvallis, OR: Oregon State College.

Elton CS. 1958. The Ecology of Invasions by Animals and Plants. Springer US.

Environmental Protection Agency 2015. Climate Change Indicators in the United States: U.S. and Global Temperature. Washington, D.C.

ESRI 2013. ArcGIS Desktop: Release 10.1. Redlands, CA: Environmental Systems Research Institute.

Gotelli NJ, Colwell RK. 2001. Quantifying biodiversity: procedures and pitfalls in the measurement and comparison of species richness. Ecology letters 4:379-391.

Hagar JC. 2007. Wildlife species associated with non-coniferous vegetation in Pacific Northwest conifer forests: A review. Forest Ecology and Management 246:108-122.

Hagar JC, McComb WC, Emmingham WH. 1996. Bird communities in commercially thinned and unthinned Douglas-fir stands of western Oregon. Wildlife Society Bulletin:353-366.

Hammer Ø. 2013. PAST: Palaeontological Statistics, ver. 3.0 Reference manual.

Hennings LA, Edge WD. 2003. Riparian bird community structure in Portland, Oregon: habitat, urbanization, and spatial scale patterns. The Condor 105:288-302.

Holmes RT, Sherry TW. 1988. Assessing population trends of New Hampshire forest birds: local vs. regional patterns. The Auk 104:756-768. 
573

574

575

576

577

578

579

580

581

582

583

584

585

586

587

588

589

590

591

592

593

594

595

596

597

598

599

600

601

602

603

604

605

606

607

608

609

610

611

612

613

614

615

616

617

618
Holmes RT, Sherry TW. 2001. Thirty-year bird population trends in an unfragmented temperate deciduous forest: importance of habitat change. The Auk 118:589-609.

Ig1 LD, Johnson DH. 2005. A retrospective perspective: evaluating population changes by repeating historic bird surveys. USGS Northern Prairie Wildlife Research Center:Paper 49.

Illán JG, Thomas CD, Jones JA, Wong W-K, Shirley SM, Betts MG. 2014. Precipitation and winter temperature predict long-term range-scale abundance changes in Western North American birds. Global Change Biology 20:3351-3364.

Knick ST, Rotenberry JT. 2000. Contribution of landscape change to current habitats used by shrubland birds. Ecology 81:220-227.

Loreau M, Mouquet N. 1999. Immigration and the maintenance of local species diversity. The American Naturalist 154:427-440.

MacArthur R. 1955. Fluctuations of Animal Populations and a Measure of Community Stability. Ecology 36:533-536.

Magurran AE, Baillie SR, Buckland ST, Dick JM, Elston DA, Scott EM, Smith RI, Somerfield PJ, Watt AD. 2010. Long-term datasets in biodiversity research and monitoring: assessing change in ecological communities through time. Special Issue: Long-term ecological research 25:574-582.

Marshall DB, Hunter MG, Contreras A. 2003. Birds of Oregon: a general reference. Oregon State University Press.

Marzluff JM. 2014. Welcome to Subirdia: Sharing Our Neighborhoods with Wrens, Robins, Woodpeckers, and Other Wildlife. Yale University Press.

McCann KS. 2000. The diversity-stability debate. Nature 405:228-233.

McKinney ML, Lockwood JL. 1999. Biotic homogenization: a few winners replacing many losers in the next mass extinction. Trends in Ecology \& Evolution 14:450-453.

Mikkelson GM, McGill BJ, Beaulieu S, Beukema PL. 2011. Multiple links between species diversity and temporal stability in bird communities across North America. Evolutionary Ecology Research 13:361-372.

Nichols JD, Boulinier T, Hines JE, Pollock KH, Sauer JR. 1998. Estimating rates of local species extinction, colonization, and turnover in animal communities. Ecological Applications 8:1213-1225.

NOAA National Climatic Data Center 2015. NOAA/NCDC Global Historical Climatology Network (GHCN) - Daily Summaries from Corvallis State University. Subset used: May 1952-July 2013.

Oksanen J, Blanchet FG, Kindt R, Legendre P, Minchin PR, O’Hara RB, Simpson GL, Solymos $\mathrm{P}$, Stevens MHH, Wagner H. 2013. vegan: community ecology package.

Parody JM, Cuthbert FJ, Decker EH. 2001. The effect of 50 years of landscape change on species richness and community composition. Global Ecology and Biogeography 10:305-313.

Ralph CJ, Sauer JR, Droege S. 1998. Monitoring bird populations by point counts. DIANE Publishing.

R Core Team 2013. R: A Language and Environment for Statistical Computing. Vienna, Austria: R Foundation for Statistical Computing.

Ricklefs RE. 1987. Community diversity: relative roles of local and regional processes. Science 235:167-171.

Root T. 1988. Environmental factors associated with avian distributional boundaries. Journal of 
619

620

621

622

623

624

625

626

627

628

629

630

631

632

633

634

635

636

637

638

639

640

641

642

643

644

645

646

647

648

649

650

651

652

653

654

655

656

657

Biogeography 15:489-505.

Rotenberry JT, Wiens JA. 2009. Habitat relations of shrubsteppe birds: a 20-year retrospective habitat. The Condor 111:401-413.

Sauer JR, Hines JE, Fallon JE, Pardieck KL, Ziolkowski DJ Jr, Link WA. 2014. The North American Breeding Bird Survey, results and analysis 1966-2012. Version 02.19.2014.

Seavy NE, Alexander JD. 2011. Interactive effects of vegetation structure and composition describe bird habitat associations in mixed broadleaf-conifer forest. The Journal of Wildlife Management 75:344-352.

Shultz AJ, Tingley MW, Bowie RCK. 2012. A century of avian community turnover in an urban green space in northern California. The Condor 114:258-267.

La Sorte FA, Boecklen WJ. 2005. Changes in the diversity structure of avian assemblages in North America. Global Ecology and Biogeography 14:367-378.

La Sorte FA, Thompson III FR. 2007. Poleward shifts in winter ranges of North American birds. Ecology 88:1803-1812.

Stralberg D, Jongsomjit D, Howell CA, Snyder MA, Alexander JD, Wiens JA, Root TL. 2009. Re-shuffling of species with climate disruption: a no-analog future for California birds? PLoS ONE 4:e6825.

Strohbach MW, Hrycyna A, Warren PS. 2014. 150 years of changes in bird life in Cambridge, Massachusetts from 1860 to 2012. The Wilson Journal of Ornithology 126:192-206.

Temple SA, Wiens JA. 1989. Bird populations and environmental changes: can birds be bioindicators. American Birds 43:260-270.

Thomas CD, Lennon JJ. 1999. Birds extend their ranges northwards. Nature 399:213-213.

Tingley MW, Beissinger SR. 2009. Detecting range shifts from historical species occurrences: new perspectives on old data. Trends in Ecology \& Evolution 24:625-633.

US Department of Agriculture, Farm Service Agency 1956. Benton County Aerial Photographs.

US Department of Agriculture, Farm Service Agency 2012. National Agriculture Imagery Program (NAIP).

US Geological Survey 2012.National Gap Analysis Program (GAP). Available at http://gapanalysis.usgs.gov/ (accessed March 5, 2013).

USGS Patuxent Wildlife Research Center 2013.North American Breeding Bird Survey FTP data set, version 2013.0. Available at ftp://ftpext.usgs.gov/pub/er/md/laurel/BBS/datafiles/ (accessed January 12, 2013).

Vale TR, Parker AJ, Parker KC. 1982. Bird communities and vegetation structure in the United States. Annals of the Association of American Geographers 72:120-130.

Vitousek PM, Mooney HA, Lubchenco J, Melillo JM. 1997. Human Domination of Earth's Ecosystems. Science 277:494-499.

Williams JW, Jackson ST. 2007. Novel climates, no-analog communities, and ecological surprises. Frontiers in Ecology and the Environment 5:475-482. 


\section{Table $\mathbf{1}_{\text {(on next page) }}$}

Observed and Chao 1 estimated number of species (S).

Richness calculated across all sites and by individual sites. Values for the modern data were calculated for the entire dataset as well as for the data after removing non-visual detections to better replicate historic survey methods. 95\% confidence intervals for Chao's estimated number of species are provided in parentheses. * indicates a significant increase in estimated richness compared to historic values. 


\begin{tabular}{lllll} 
Site & Richness Measure & 1952 & 2013 (All Detections) & 2013 (Visual Only) \\
Overall & Observed S & 79 & 101 & 85 \\
& Chao1 S & $87(79-99)$ & $116(101-134)$ & $109(85-137)$ \\
Coniferous & Observed S & 32 & 36 & 19 \\
& Chao1 S & $33(32-40)$ & $46(36-78)$ & $24(19-58)$ \\
Marsh & Observed S & 34 & 61 & 51 \\
\multirow{2}{*}{ Mixed Deciduous } & Observed S & 32 & 43 & $55(51-62)^{*}$ \\
& Chao1 S & $33(32-36)$ & $46(43-53)^{*}$ & 36 \\
\multirow{2}{*}{ Oak Woodland } & Observed S & 25 & 52 & $42(36-57)$ \\
& Chaol S & $25(25-28)$ & $58(52-72)^{*}$ & 31 \\
Willamette & Observed S & 27 & 46 & 36
\end{tabular}




\section{Table 2 (on next page)}

Simpson's diversity values (1/D) for historic and modern survey eras.

$95 \%$ confidence intervals are provided in parentheses. * indicates significantly different modern diversity compared to historic values (Paired t-test, $p<0.05$ ). 


$\begin{array}{llll}\text { Site } & 1952 & 2013(\text { All Detections) } & 2013 \text { (Visual Only) } \\ \text { Overall } & 9.28(8.66-9.93) & 30.90(29.62-31.91)^{*} & 23.47(22.04-24.58)^{*} \\ \text { Coniferous } & 15.93(13.51-17.33) & 13.95(12.64-14.93) & 7.15(6.01-8.10)^{*} \\ \text { Marsh } & 3.14(2.97-3.33) & 10.89(10.14-11.66) * & 9.63(8.84-10.42)^{*} \\ \text { Mixed Deciduous } & 12.24(10.51-13.66) & 12.92(11.44-14.26) & 11.11(9.45-12.5) \\ \text { Oak } & 11.12(9.63-12.21) & 12.19(10.67-13.7) & 7.55(6.54-8.6)^{*} \\ \text { Willamette } & 12.69(11.34-13.41) & 12.08(10.93-13.14) & 10.73(9.15-12.06) \\ & & & \end{array}$




\section{Table 3(on next page)}

Local species turnover between 1952 and 2013.

Values \pm SE. Estimates represent the probability that a randomly selected species was "new" to the species pool during the modern survey period. Standard errors were derived from nonparametric bootstrapping methods. 
Site $\quad$ All Detections (\%) Visual Only (\%)

$\begin{array}{lll}\text { Overall } & 39.3 \pm 6.2 & 48.3 \pm 6.7\end{array}$

$\begin{array}{lll}\text { Coniferous } & 55.7 \pm 10.7 & 68.3 \pm 3.5\end{array}$

$\begin{array}{lll}\text { Marsh } & 63.6 \pm 12.3 & 64.0 \pm 7.3\end{array}$

Mixed Deciduous $\quad 58.1 \pm 5.0 \quad 59.1 \pm 4.5$

Oak Woodland $\quad 70.2 \pm 6.5 \quad 75.2 \pm 3.0$

$\begin{array}{llr}\text { Willamette } & 58.9 \pm 8.1 & 54.1 \pm 6.9\end{array}$ 


\section{1}

Estimates of regional species richness and turnover between 1968 and 2012.

Mean values of richness (number of species) and turnover (probability of a species being replaced) for the regional avian community from 1000 iterations of individual-based rarefaction $(n=825)$ for each year. Species richness estimates are represented by black dots, while turnover estimates are represented by red squares. Black line is a smoothed loess fitted to richness data to represent trend. Red dashed line is a simple linear regression of species turnover $\left(R^{2}=0.01\right)$. Regional data obtained from 10 Willamette and Umpqua Valley Breeding Bird Survey routes geographically similar to the local study area.

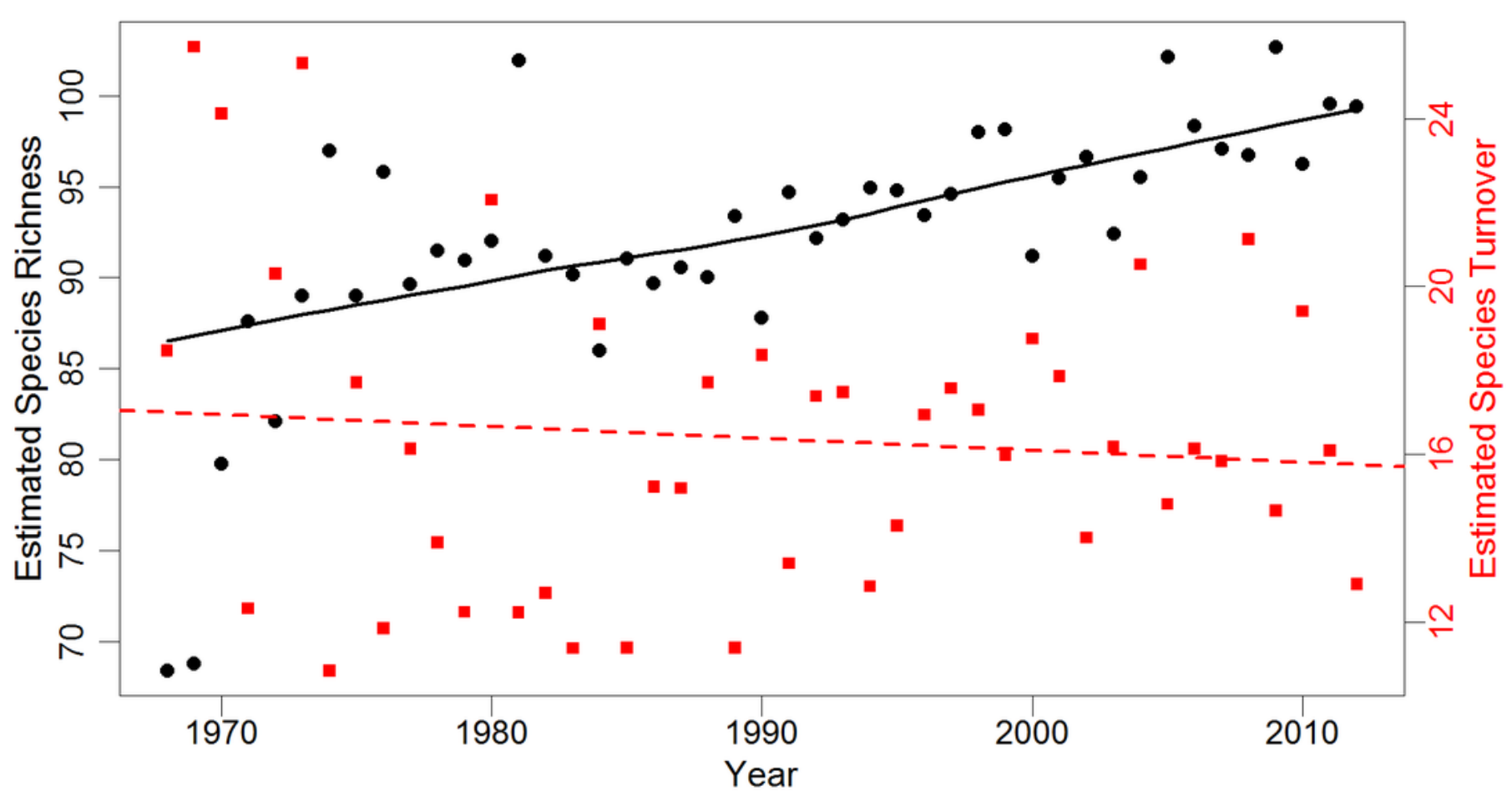

